\title{
Modeling the Relational Structure of Ancient Societies through the Chaîne opératoire: The Late Chalcolithic Societies of the Southern Levant as a Case Study
}

\author{
Valentine Roux
}

\section{Introduction}

In archeology, modeling evolution processes is a major issue. The goal is to explain cultural variation over space and time in light of general evolutionary mechanisms inheritance, interaction, and local adaptation (Shennan et al. 2015). Modeling these processes is done using different tools (computational models, simulations; for a review, see Cegielski and Rogers 2016). General evolutionary models exploring cultural transmission for explaining changes in material culture through time are mainly found in evolutionary and network archeology. As a way to introduce the methodological questions dealt with in this paper, I first briefly recall what these two modeling approaches aim at.

In evolutionary archeology, models aim at interpreting artifact changes in terms of mode of transmission (number of people involved, direction in which information is passed - phylogenesis versus ethnogenesis - biased forms of transmission, and how information is packaged; Eerkens and Lipo 2007). Studying modes of transmission implies to understand how information is acquired and transformed by individuals through microevolutionary process (selection, mutation, drift). These models quantify the effects of sociopsychological mechanisms in time (e.g., copying the most prestigious, conforming to the majority, copying with errors; Mesoudi 2009) and offer reference patterns of variability depending on the modes of transmission (e.g., Bentley and Shennan 2003; Bettinger and Eerkens 1999; Jordan and Shennan 2003; Shennan and Wilkinson 2001; Tehrani and Collard 2009). They thus aspire to explain the large-scale patterns observed in the archeological record by extrapolating microevolutionary processes in time and space (Mesoudi and O'Brien 2009) and investigating the spatial and temporal structure of cultural variation

\footnotetext{
V. Roux $(\bowtie)$

CNRS, UMR 7055, University Paris-Nanterre, Nanterre, France

e-mail: valentine.roux@cnrs.fr
} 
(Shennan et al. 2015). Although transmission of information is acknowledged to occur at the level of the group (Mesoudi and O'Brien 2009), the context into which information is transmitted is less explored (except for the size of the population; O'Brien and Bentley 2011; Powell et al. 2010; Shennan 2001).

These evolutionary models raise several questions. One of them is the nature of the traits used in these models. They are mainly morphocentric (i.e., modeling evolution of morphometrical traits) (Dunnell 1978; Eerkens and Lipo 2005; Gandon et al. 2014; Hamilton and Buchanan 2009; Neiman 1995; O'Brien et al. 2010; Shennan and Wilkinson 2001) and ignore technological traditions which can be defined as inherited ways of doing things and which require to be described with other traits (Charbonneau 2018). Secondly interpretation of the evolution of traits is reduced to elementary mechanisms of change (e.g., interpreting evolution in terms of types of learning - unbiased transmission versus bias transmission), whereas these elementary mechanisms are not sociological regularities (specifying the social structure within which these mechanisms operate). As such, they can measure the change (its direction, tempo, and scale), but cannot be used for explaining why certain social structures are more favorable than others to evolution processes (e.g., why cultural diffusion occurs in some places rather than in others) and therefore for bringing to light potential evolutionary laws explained by social facts that we could use to interpret evolutionary processes (Gallay 2011).

In contrast, analytical sociology focuses mainly on the relational structure of societies, namely, the social network, within which information is transmitted and diffused (Axelrod 1997; Valente 1999; Valente 1996). Network models are used to relate individual actions (micro-level), the interdependence structures between those actions (the interactions between the units, meso-level), and the sociological regularities emerging from the latter (macro-social generalizations) (Manzo 2007, 2014). These models use simulation methods, including multi-agent system. ${ }^{1}$ The ambition of this method is to unveil the mechanisms explaining how regularities are created, knowing that it is not enough to produce a result for claiming that the activated individual actions are the explanatory factors. For this reason individual actions are considered in relationship with different types of interactions (the interdependence structures) in order to understand better how some individual actions can generate macro-social regularities. Thus for the purpose of explaining the social conditions favorable to innovation or diffusion of cultural traits, individual actions are simulated within different network structures (i.e., homogeneous versus heterogeneous; Flache 2018; Flache and Macy 2011; Granovetter 1983; Rogers 1962). In these models, the content of the information is also measured (Rogers 1962), the spread of information considered as depending on both the network structures and the content of what is being transmitted (Centola 2015; Centola and Macy 2007).

\footnotetext{
1 "a multi-agent system is made up of a set of $\mathrm{n}$ elementary units (named 'automata' or 'agents'). The researcher can program both the behavior of these units, either singly or grouped into subsets, and the way the units (or group of units) interact in time. The aim of the technique is to observe how the system of interaction between agents evolve and its final 'emerging' configuration" (Manzo 2007, p. 49).
} 
Like the models used in evolutionary archeology, simulations from analytical sociology are based on individual actions grounded in sociopsychological rules. However, because these individual actions are considered in different contexts of interactions and thus the meso-level modeled for understanding the micro-macro problem (Manzo 2007: 51), the regularities produced offer hypotheses about the social structures favorable to changes. These regularities are looked for in archeology because they provide explanations to correlates between social structure and changes, knowing that explanatory mechanisms underlying these correlates cannot be studied in archeology given the lacunar aspect of the documentation. In other words, archeological data may allow us to describe processes of change in terms of mode of transmission (e.g., ethnogenesis versus phylogenesis); however they do not allow us to test why a specific social structure was favorable to change (e.g., why it favored or not social influence and led or not to assimilation). Such a test can be done only based on actualist data, no matter the computational tools used, because explanatory mechanisms refer to individual actions that cannot be explored in the past.

In light of this, understanding cultural processes by reference to sociological regularities raises a major issue: the characterization of ancient network structures. This characterization is necessary for a comparison with simulated network structures in order thereafter to benefit, by analogy, of the regularities associating network structure and process of change (e.g., relationship between weak ties ${ }^{2}$ and diffusion) and the explanations given to the role of social structure in the processes of change (e.g., why weak ties favor diffusion). In archeology, network analysis has been applied mainly to reconstruct ancient interregional connection networks (Brughmans 2010, 2013; Collar et al. 2015; Knappett 2011; Östborn and Gerding 2014). Local networks and therefore the relational structure of societies are less studied even though they are acknowledged to be determinant for understanding evolutionary phenomena (Blake 2014; Knappett 2018). This is partly due to difficulties in finding relevant proxies for inferring social relationships between sites. The same issue applies when investigating cultural groups or phylogenetic links (Perlès 2013; Shennan et al. 2015).

In this respect, the interpretation of archeological data, whether using computational or simulation tools, faces two main methodological issues, discussed here: (1) the variables for expressing the relational structure of a society and (2) the use of sociological models for explaining evolution process, taking account of the lacunar and polysemic nature of archeological data.

Both issues are discussed in light of an archeological case study which raises the question of the social context wherein new ceremonial objects along major technical innovations were adopted by southern Levant rural communities during the Late Chalcolithic period (4500-3900 cal. BC), also called the Ghassulian (Gilead 2011). Two extreme scenarios were elaborated, respectively, by Gilead (1988) and Levy

\footnotetext{
${ }^{2}$ Ties can be strong or weak. In analytical sociology, "strong ties describe frequently activated relationships (such as family/kin ties) whereas weak ties are used to describe infrequently accessed connections (acquaintances)" (Collar et al. 2015, p. 23).
} 
(1995) for explaining both the presence of prestige objects and the absence of any influential central site (Rowan and Golden 2009). According to Gilead (1988), the Ghassulian societies were egalitarian given the absence of monuments or building indicating chiefs, tombs with rich funerary objects, hierarchy between and within the villages, and common storage facilities. The new objects in copper, basalt, or exotic stones may testify to ritual activities without necessary elites responsible for their production. Against this hypothesis, Levy (Levy and Holl 1988; Levy 1995) considers that the material culture of the Ghassulian societies points to ranked social hierarchies with a politico-religious power, controlling the resources of the territories and redistributing them. Corresponding evidence includes specialized craftsmanship, burial caves with rich goods, pilgrimage places, hierarchized organization of settlements, and, finally, the function of metal objects pointing toward elites. Another hypothesis, based on the ceremonial function of wheel-made bowls, suggests that the invention of the potter's wheel emerged following the demand of wheel-shaped bowls by an elite (Roux 2010). In this hypothesis, the term "elite" has remained vague and does not imply any specific politico-religious s ystem. The debate is still vivid as more evidence of so-called prestige objects points toward complex networks of production and distribution and interconnected ties between communities sharing similar norms (Rosenberg et al. 2016; Rowan and Golden 2009). More generally, the debate relates to both the connections between the Ghassulian communities and the historical process which led to major changes in the material culture.

This paper is organized in three sections. The first one discusses similarity variables for assessing social relationships between sites. The second section analyzes archeological data and shows how technological attributes are meaningful qualitative data for establishing social links between sites and revealing social topology, i.e., the overall arrangement of social ties in which actors are embedded, as well as population structure, i.e., instances where individual subpopulations/groups exhibit low within and high between variability (Shennan et al. 2015). The third section discusses modeling evolution processes on the basis of qualitative variables and explaining these processes by reference to sociological models.

\section{Technological Traditions: Similarity Attributes and Social Connections}

As noted before, the variables used in archeological models are mainly morphometric and stylistic variables (i.e., size and shape of objects, decorating elements). These are used to create links between sites and assess against temporal and spatial data whether these links indicate either a cultural group or connections at a macroregional scale.

In network analysis, social relationships between sites are mostly inferred from the co-occurrence of artifacts (the more shared artifacts, the stronger the relationships; 
Collar et al. 2015). The underlying principle is that shared similar artifacts express interactions between sites or within sites and, therefore, social relationships (Coward 2013). In other words, similar artifacts are variables to measure social interactions, while the resultant network expresses a network of exchanges. Indeed, in network studies interactions are mainly considered as the expression of exchange-based relationships (Gjesfjeld and Phillips 2013). Now, this link between interactions and exchange is not straightforward. Indeed, material culture presents different aspects, and the presence of a same type of object on two sites can be due to numerous reasons: one of the two objects may be imported, copied, and made by migrants, on brokers' requests (indirect contacts), by individuals of a social group scattered over a large region, etc. Depending on the situation, similarity objects express different types of interactions between groups: exchange-based relationships, market distribution, ethnic affiliation, matrimonial alliances, movements of individuals or populations, etc. It means that when listing similarity attributes, if they are of one kind (one type of pots), which is the case most of the time (Östborn and Gerding 2014, p. 79; Östborn and Gerding 2015), the networks obtained express relationships which can be of different types.

In this sense, the issue relates to both the type of social interactions one wants to measure and the variables to use depending on the type of social interactions to highlight. As said before, much of the archeological use of network analysis targets interregional connections between sites and exchange-based relationships. On the contrary local networks have been less considered (Knappett 2018). When studied, these local networks are modeled based on probable interactions among sites sharing consumption of objects, for example, given similarities in proportion to decorated ceramics present at pairs of sites (Borck et al. 2015; Mills et al. 2013). Interactions are thus measured through the sharing of attributes, but the social content of these interactions is not measured because similarity objects can be the result of different types of interactions, making difficult to explore the strength of the links in between and within the sites as well as network topologies.

\section{Variables to Socially Linked Individuals/Groups}

In contrast, we propose to consider the ceramic chaîne opératoire as a robust variable for assessing degrees of connections between sites. It is defined as the series of actions that transform raw material into finished product, either consumption object or tool (Creswell 1976, p. 13). Its description implies the characterization of objects in terms of manufacturing methods, techniques, and tools. A method is defined as an ordered sequence of functional operations carried out by a set of elementary movements for which different techniques can be used. A technique is defined as the physical modalities used to transform the raw material into a finished product. Techniques are in limited number, contrary to methods whose variability is - theoretically - infinite. Thus if techniques can be the object of convergence, on the contrary, methods are more likely to be specific. In other words, this is the unique 
combination of sequences, gestures, and techniques that makes technological traditions highly cultural and unique to social groups, therefore distinguishing between traditions linked through the transmission of information and convergent solutions to specific situations (Shennan 2002, p. 73).

The transmission of chaînes opératoires involves constraints. Indeed, studies in the anthropology of techniques and cultural transmission show that transmission of craft techniques necessarily requires social learning, that is to say, learning from tutors contrary to individual learning (O'Brien and Bentley 2011, 317). Guided transmission of skills consists in educating the learner about the information available in the environment, be it the properties of the material, the tools used, or the effects of the gestures employed (Bril 2002). This guidance not only facilitates the learning process but also participates in the reproduction of the task (Tehrani and Riede 2008). It is the key to the cultural transmission of ways of doing things. The tutor is usually selected within one's social group (Gosselain 2000; Shennan 2013; Shennan and Steele 1999). As a result, technological traditions signal that individuals having the same tradition belonged to the same once "community of practice," i.e., a community sharing ways of doing (Lave and Wenger 1991). This term might seem awkward when used for connecting sites since communities of practice are defined as groups of people who interact regularly (Wenger 2000), whereas in archeology it is problematic to demonstrate regularity of interactions. "Community of practice" is to be better understood as a process, a mechanism which explains how traditions are created (in the course of learning), perpetuated, or modified (Gosselain 2008). In archeology, similarity between ways of doing can be seen as the result of this process, however spread out in time and space, and therefore signaling before all communities made up of individuals who learned and taught a same craft tradition within the framework of historically determined social links. Spatial patterns of these communities can be the result of both historical and sociocultural processes: population expansion and/or sociocultural circulation of individuals (e.g., through matrimonial alliances). On the contrary, dissimilarity in craft techniques between sites signals different communities, that is, communities whose individuals do not share the same practices and therefore are not part of the same social group. Similarity or dissimilarity in craft techniques can thus link sites and bring to light social communities and locally driven networks, similarity indicating strong ties, and dissimilarity, weak ties. The overall spatial arrangement of technological traditions reflects population structure (Hodder 1985; Roux et a 1. 2017; Stark et al. 2008; Stark 1998).

Let us note that in ceramic technological traditions, the longest stage to learn is the forming stage because of the general difficulty of mastering motor skills (Bril 2002; Ericson and Lehman 1996). Forming techniques are taught with a tutor over years usually within private spaces, while shapes, decorative features, or even clay recipes can be learned through individual learning after seeing objects in public spaces and/or discussing with retailers (e.g., interactions with shopkeepers) (Roux 2015). As a consequence, forming techniques tend to be more resistant to change than easily transmissible traits such as style (shapes and decor of objects) (Gallay 2007; Gelbert 2003; Gosselain 2000; Hegmon 1998; Mayor 2010; Roux 2015; 
Stark et al. 2000). In this respect forming technique is a better variable to connect over time individuals/communities from the same social group than shapes and decoration whose evolutionary mechanisms make them more subject to rapid changes and diversity, even within the same social group. It must therefore be remembered that, when submitted to evolution (either through phylogenesis or ethnogenesis process), the different stages of the chaînes opératoires are meant to change at different rhythms because they are subject to different mechanisms of change. Each of them should be considered as a distinct variable, signaling different types of interactions depending on their co-occurrence.

\section{Variables to Measure Network Topology}

In social network analysis, assessing connections between groups implies not only to assess the similarity between groups but also to examine the embeddedness of the network and therefore the network topology. Embeddedness is "an indicator of how a particular individual or social group will socially interact by either choosing to network with many other individuals or only a few" (Borck et al. 2015, p. 37). The examination of embeddedness quantifies "how a particular group is likely to interact with its neighbors at a given point in time and how that may affect the network and actors during later temporal intervals" (Borck et al. 2015, p. 37). Different quantifying methods are used. For example, ceramic types are apportioned into time intervals (Mills et al. 2013). Measures of similarity between sites are based on the relative percentages of apportioned ceramic types between pairs of sites. In order to calculate connections inside the regions and outside the regions, and therefore embeddedness at the population level, groups are made based on independent criteria (archeological and geographical boundaries). These quantified measures require a high chronological resolution which unfortunately is not often the case.

A qualitative approach to embeddedness is the composition of the ceramic assemblages at the macro-regional scale (Roux 2016, chap. 4). This composition may testify to interactions between communities at different scales. In this aim, ceramic assemblages are analyzed in terms of techno-petrographic homogeneity versus heterogeneity. Theoretically, we distinguish two categories of ceramic assemblages - homogeneous and heterogeneous assemblages - on the basis of techno-petrographic groups (groups including ceramics made the same way with the same clay material). Simple homogeneous assemblages (made of one technopetrographic group) characterize sites whose producers belong to a homogeneous social group and use clay on site. Complex homogeneous assemblages ( $n$ technopetrographic groups) characterize sites with distinct groups of producers using different clay sources close from the site. Simple heterogeneous assemblages reveal diverse techno-petrographic groups. Petrographic heterogeneity indicates ceramic production on a meso-regional scale, and the low variability of this heterogeneity allows us to define the region of the clay material sources. Complex heterogeneous assemblages reveal diverse techno-petrographic groups. Due to petrographic 
heterogeneity, and marked variability, it is not possible to define a single region, and ceramic production sites are dispersed over a macro-regional scale. Simple and complex heterogeneous assemblages testify at a given point in time to the presence of consumers originating from the meso- or macro-region of the site. The former point to embeddedness at the regional level and the latter to embeddedness at the population level.

In brief, the techno-petrographic analysis of ceramic assemblages at a macroregional scale should enable us to highlight whether there are movements of individuals between sites and whether these movements indicate interactions. In a macro-region where sites are recognized as epicenters of interactions, these sites indicate strong network embeddedness.

\section{Connecting Ghassulian Sites with Technological Traditions}

In this section, we show how the chaîne opératoire approach enables us to link the Ghassulian sites of the southern Levant. The artifacts characterizing the Ghassulian culture as a "coherent culture" and connecting the sites are first recalled, followed by the technological ceramic analysis.

\section{Shared Ceremonial Objects in the Southern Levant During the Ghassulian Period}

The Ghassulian sites of the southern Levant (Fig. 1) were occupied by agropastoral communities who indisputably shared mundane material culture (repertoire of ceramic vessels, lithic tools, grinding material), iconographic motifs, mortuary practices, and ceremonial objects, suggesting a coherent culture (Lovell and Rowan 2011; Rowan and Golden 2009).

The size of the sites and their spatial patterning do not point toward hierarchy or some sort of centrality. A few sites range up to 10 ha; a few others are large (c. 4-5 ha). However, most of the sites are small (c. $<1-2$ ha). The relationship between larger and smaller sites remains unknown (Levy et al. 2006). The village houses are broadly similar from the Golan to the Negev. Within sites, there is no size differentiation, hierarchy in room sizes, or obvious elite areas.

The social relationships between sites are difficult to assess mostly because of a lack of chronological control. Indeed, the Ghassulian period of the southern Levant is probably divided in two phases, as shown by researches in the northern Negev (Gilead 2011). However, these phases have not been distinguished on most sites because there is practically no change in stratigraphy and the artifactual assemblages (Gilead 1994; Rowan and Golden 2009); at this stage, one can just keep in mind that variability in some patterns could be chronological. 


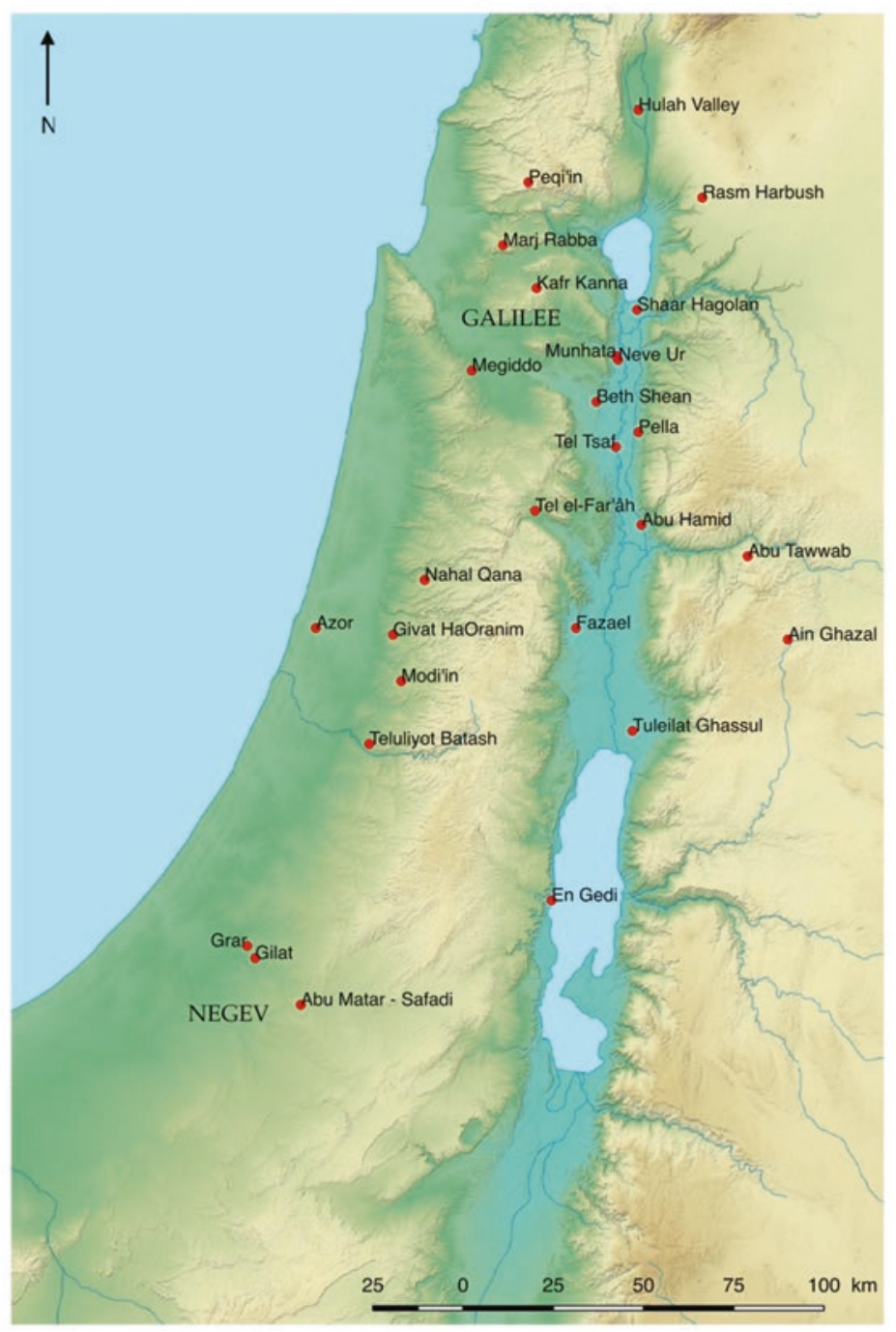

Fig. 1 Sites and regions of the southern Levant cited in the text

This being said, there are shared objects between sites, providing evidence for local networks. The most conspicuous are the so-called ceremonial/prestige objects whose distribution highlights patterns at different regional scales. They are the ones considered here as they testify to shared symbolic norms among which some emerged along with major technical innovations, such as wheelshaped bowls and the wheel-coiling technique and copper objects and the lostwax technique. They include basalt vessels, wheel-shaped bowls, perforated flint tools, stone violin figu-rines, maceheads, copper objects, and ivory objects. As we shall see, basalt bowls, wheel-shaped bowls, violin figurines, and maceheads connect sites from all over the 
southern Levant, while perforated flint tools and ivory and copper objects are more regionally distributed.

\section{Regional Distribution}

Perforated flint objects are unique items whose distribution is marked geographically. They are interpreted as prestige objects because they require high knapping skills, show surprisingly limited use, and are found in both domestic (settlement) and ritual contexts (burial caves) (Rosen 1997; Rosenberg and Shimelmitz 2017). Their distribution reflects a northern network, including sites of the Jordan Valley.

Ivory and copper items are the two other categories of prestige/ceremonial objects to circulate within a geographically constrained network. They are found mainly in the southern regions. Copper artifacts, probably produced in ritualized contexts, were made locally as shown by production artifacts on the Beersheva sites (Goren 2014; Gilead and Gošić 2015).

\section{Macro-regional Distribution}

However, there is a distribution of ivory and copper items at the macro-regional scale, although it is restricted to three pivotal collective burial caves: Nahal Qanah, Giv'at Ha-Oranim, and Peqi'in. On the basis of their context of finding, metal ceremonial objects have been interpreted as a burial kit of graves (along goods like ivory, basalt, textiles, and ceremonial ceramics) involving multiple burials and, oftentimes, secondary burials associated with ossuaries (Golden 2009). In this respect, they indicate both sharing of mortuary practices and norms over a wide area, from Negev up to Galilee, even though their fabrication was restricted to the northern Negev.

Basalt vessels are found in most Ghassulian settlements throughout the southern Levant, most typically in domestic contexts. They are supposed to be prestige/ceremonial objects, given the skills involved in their manufacturing and the long distance between the basalt sources (east in Jordan or north in the Galilee and Golan) and many of the sites where they have been found (Chasan and Rosenberg 2018). Moreover, numerous basalt vessels are reported in eight Ghassulian burial caves arguing in favor of their interpretation as highly valued objects (Chasan and Rosenberg 2018). Their wide dispersion throughout the region, in ceremonial or domestic sites, reflects a far-reaching macro-regional network (Rosenberg et al. 2016).

Wheel-shaped bowls are also found all over the southern Levant in settlements and funerary contexts. They are supposed to be ceremonial objects (lamps as shown by soot traces). The main arguments are as follows: (a) the wheelcoiling technique implies specialized skills that are in play only for this category of bowls, henceforth making them highly valued objects, and (b) their presence in funerary contexts is systematic whatever the type of burial and the geographical zone (Roux 2003). 
These bowls were produced on-site. They are supposed to have been made by itinerant potters (Roux and Courty 2005). In this regard, they testify to movements of individuals from site to site arguing in favor of strong connections between the sites.

The violin figurines and the stone maceheads, whose raw material is varied and originates possibly from different geographical zones, have been found in a limited number of sites but throughout southern Levant, from north to south. Like the basalt vessels, they testify to shared norms through the consumption of the same category of objects by geographically dispersed communities.

\section{Distribution of Ceremonial Objects at Different Scales}

In summary, specific patterns of distribution of ceremonial objects reflect networks at different scales, regional versus macro-regional networks, and different time periods.

Regional networks distinguish roughly between northern/eastern and southern/ western clusters of sites. The northern/eastern cluster gathers sites in northern Israel (Golan, Hula valley, the Galilee), the Middle Jordan Valley, northern Jordan, and southern Syria, through the circulation of perforated flint tools. The southern/western cluster gathers sites mainly from the Shephelah - littoral coast southward through the manufacture and use of copper objects and the circulation of ivory objects. Within each of these regions, smaller-scale geographical zones can be highlighted when examining the provenance of the ceramics found on ceremonial or burial places. Thus petrographic analysis of Gilat, a supposedly ceremonial place in the northern Negev, highlights that it was a center for the northern Negev and the Judean mountains (Goren 1995), whereas En Gedi, a shrine above the Dead Sea, was frequented by individuals from the Judean mountains only (Goren 1995; Roux and Courty 2007). In this respect, regional ceremonial places could correspond to local cults coexisting with a macro-regional cult (Gilead 2002). The unique basalt pillar figurines of Golan, found in household contexts, echo these local cults; similarly, regional burial caves such as in Azor where ceramic bowls have been found to be produced within a meso-region (30 km around) echo local networks (Roux and Courty 2007).

The macro-regional network testifies to the sharing of the same ceremonial norms through the use of basalt bowls, wheel-shaped bowls, violin figurines, and maceheads. This macro-regional network is apparently active during the whole Ghassulian period (early and late). It is also visible in the funerary goods found at three pivotal burial caves: Peqi'in, Nahal Qanah Cave, and Giv'at Ha-Oranim. These caves (probably late Ghassulian), characterized by multiple burials deposited over time, are exceptional in the way they gather ceremonial objects that are either shared at the macro-regional scale (basalt bowls, wheel-shaped bowls) or at the regional scale only (perforated flint object from the northern network, copper and ivory items from the southern network) (Rosenberg and Shimelmitz 2017). They thus indicate shared ceremonial norms between communities integrated also within 
distinct regional networks, notwithstanding a variety of burial practices within southern Levant.

In order to debate whether the sharing of norms as expressed by ceremonial artifacts across the southern Levant was encouraged by a hierarchy or by the social structure itself, local connections between sites remain to be drawn. These connections will be tentatively highlighted on the basis of the ceramic chaînes opératoires used for making the mundane ceramic vessels.

\section{Ghassulian Local Networks: The Ceramic Chaînes Opératoires}

For assessing qualitatively the degree of interactions between sites and drawing hypothesis about social topology, the chaînes opératoires carried out for making the mundane containers constitutive of the ceramic assemblages have been analyzed in terms of similarity/dissimilarity.

The sites are located in different parts of the southern Levant ${ }^{3}$ (Fig. 1). Ceramic assemblages belong to well-established Ghassulian horizons even though the chronological span can cover a few hundred years.

\section{The Chaînes Opératoires: Connecting Sites}

Results highlight that the same chaîne opératoire was carried out by all the Ghassulian communities of the southern Levant (Roux 2019). It entails the following operations. Clay material is usually mixed with 20-30\% coarse mineral grains whose size depends on the thickness of the walls. Petrographic studies highlight the local production at almost all sites studied (Rowan and Golden 2009). The bases are modeled into a disc shape from a lump of clay, the edges are raised, and an inner peripheral coil is placed against the edges on the disc. The next successive coils are fixed by apposition against the inner face. Once the body is shaped, the rim is thinned and shaped with a wet piece of cloth. After shaping the rim, the inner face is smoothed with a dry or wet soft tool. The vessel is left dried until leather-hard consistency. Elements are applied at that point: decorative bands, handles, and, for all the vessels, an extra peripheral coil around the external base, probably as a reinforcement piece. A coating is then applied on the outer face for the closed vessels and on both sides for the open vessels. The decoration of the bands by finger impression is made after the coating, as well as the perforation of the handles.

There are regional variants to this chaîne opératoire, like, in the north, the application of a red slip on the coating. These variants still need to be recorded more

\footnotetext{
${ }^{3}$ The studied sites are in the Jordan Valley and the Dead Sea basin (Teleilat Ghassul, Fazael, Abu Hamid, Pella, Tel el-Far'âh [N., cave U], Neve Ur), in the Negev (Abu Matar, Safadi, Grar), in the Shephelah (Modi'in), in the coastal plain (Azor), in the Galilee (Kafr Kanna, Levels 112-115; Megiddo, stratum 5), in the Hula valley (Tel Teo, Turmus), and in the Golan (Rasm Harbush).
} 
systematically and should enable us to cluster groups interacting preferentially with one another.

\section{The Chaînes Opératoires: Population Structure}

The Ghassulian chaîne opératoire contrasts with the chaînes opératoires used during the fifth to fourth millennium BC by the neighboring populations. In Egypt, the clay paste is tempered with animal dung, the bases are made from spiraled coils, the bodies are made with horizontally superimposed coils, and the external faces are burnished. To the north of the southern Levant, several traditions are used, including shaping by modeling or by adding large coils. None of them use clay coating (Baldi 2017).

These different traditions do not stem from temporal and/or spatial factors: there are no similar technical elements which could signal a common origin. In this respect, the technological analysis of the ceramics highlights a population structure distinguishing the southern Levant population from its neighbors who were social groups within which other ways of doing ceramics were transmitted.

\section{Composition of the Ceramic Assemblages: Social Topology}

The issue lies in assessing whether the Ghassulian communities, distributed over a wide regional area, sharing the same ceramic tradition as well as ceremonial objects, but made of distinct groups based on the geographical distribution of some technostylistic variants (shapes, slip), were interacting at the population scale within an embedded social network.

A techno-petrographic study of ceramic assemblages belonging to sites distributed all over the southern Levant shows that there are three main categories of assemblages: (a) homogeneous assemblages testifying to interactions at the scale of the village, (b) simple heterogeneous assemblages testifying to interactions at the regional scale, and (c) complex heterogeneous assemblages testifying to interactions at the population scale (Roux and Courty 2007).

Simple heterogeneous assemblages indicating interactions at the regional scale are met in shrines or burial sites (e.g., Gilat, En Gedi, Azor) (Goren 1995). Complex heterogeneous assemblage is met only at one site, Abu Hamid in the Middle Jordan Valley. The techno-petrographic analysis of the ceramic assemblage shows that all the recipients come from all over the southern Levant (Roux and Courty 2007). In the Late Chalcolithic cultural context, Abu Hamid has been interpreted as a gathering/pilgrimage site, that is to say, a place frequented by people who come from all over the southern Levant. In this respect, the ceramic assemblage of Abu Hamid suggests that Ghassulian sites were connected at the population level at a given point in time and therefore that the Ghassulian population was a homogeneously mixed population (each individual can interact with one another) within a tight embedded social network. 


\section{Modeling and Explaining Evolution Processes: Phylogenetic and Sociological Models}

In the previous section, we have seen that qualitative variables such as the chaines opératoires allow to socially connect the Ghassulian sites of the southern Levant and unveil the social topology as well as the population structure. In a general similarity network analysis, i.e., "a flexible framework in which all kinds of similarity relations (including well defined differences) can be used as proxies for causal or social relationships and define links between archaeological contexts" (Östborn and Gerding 2014, p. 87, 2014), the Ghassulian chaîne opératoire can thus be added as an attribute whose presence or absence, combined with types of vessels, will be a major indicator of the relational structure of the society.

Modeling evolution processes is another issue discussed below. We distinguish between (1) modeling evolution processes through phylogenetic models for testing, in our case study, how the Ghassulian homogeneous mixing population was created and (2) explaining historical changes by transferring regularities highlighted by sociological models on archeological data.

\section{Phylogenetic Models and Technology}

Technological traditions can also be considered as relevant variables to establish cultural lineages, defined as "traditions linked by historical continuity based on the transmission of information through time" (Shennan 2002, p. 72). Indeed, traits describing the chaînes opératoires are particularly relevant as opposed to shapes because, as previously said, they are traits transmitted between producers from the same social group and therefore quite stable, contrary to shapes that are likely to evolve with the evolution of the demand (needs), to be easily copied (without necessary social learning) and consequently to change rapidly. Identifying cultural lineages implies the study of assemblages of different periods, preferentially from the same sites, and a detailed analysis of the chaînes opératoires in order to trace socially learned ways of doing vessels handed down over the centuries.

The characterization of cultural lineages is a qualitative approach but can be coded with computational tools for quantitative output. In this case, cladistics is the preferred approach, as it allows for the measurement of the phylogenetic signal linking assemblages (O'Brien et al. 2001, 2003). The construction of a phylogenetic tree is based on a simple fundamental principle: lineage with modification. The application of the phylogenetic tree to techniques allows for the modeling of the diversity of chaînes opératoires, their evolution and their kinship in a cultural group (phylogenesis), and any possible extra-cultural transfers (ethnogenesis) (Manem 2008).

In the case of the Ghassulian societies of the southern Levant, the recognition of a large rural social group occupying the whole southern Levant during the Ghassulian 
period raises the issue of how a wide social network sharing a same tradition developed. The hypothesis is that the macro-regional network finds its roots in an ancestral social network, whereas the regional networks may have emerged over time through geographical connectivity only.

To work out this hypothesis, ideally, phylogenetic modeling could measure the evolution of the ceramic traditions over centuries. A preliminary qualitative study of the ceramic assemblages from a few sites ${ }^{4}$ dated from the end of the seventh to early fifth millennium BC suggests the existence of phylogenetic links between the Neolithic and the Chalcolithic assemblages. The main chaîne opératoire involved in the making of the mundane vessels is the same as the one used during the Ghassulian period: the clay paste is prepared with a high proportion of coarse mineral temper, the bases are modeled in the form of a disc and edges raised, small coils are laid inward, reinforcing coils are laid around the outer bases, and, finally, walls are clay coated. This chaîne opératoire is the stable element while other traits evolved over time (in particular shapes and decor). It represents the ancestral trait linking the Neolithic and Ghassulian ceramic assemblages testifying to the transmission of a same way of doing from generation to generation over more than two millennia and therefore to the relationship by descent between the related communities. This relationship by descent amounts to saying that the ancestors of the Ghassulian groups were the Neolithic communities of the southern Levant. If this hypothesis is correct, ties of kinship, to varying degrees, may have united all the individuals forming the Ghassulian society of the southern Levant, explaining the Ghassulian embedded social network.

The evolving traits, creating variants between regions over time, are the derived traits. They may testify to the spatial spreading and splitting of the social groups over the two millennia separating the seventh and fifth millennia populations. Phylogenetic modeling should help to test this hypothesis by highlighting the derived traits and their possible relationships with the emergence of regionally centered ceremonial/burial places. Among the derived traits, not only technical variants but also degrees of similarities and differences in ceramic shapes between sites as a function of interactions should be taken into account.

\section{Sociological Models for Explaining Evolution Processes}

Phylogenetic models describe modification of material culture in terms of transmission. The question is how to explain these modifications in sociological terms. We believe that simulations of archeological data are not meant to provide explanations to correlations between social structure and changes. Rather, explanations have to

\footnotetext{
${ }^{4}$ They include sites from the Jordan Valley (Abu Hamid, Tel Tsaf, Beth Shean XVIII, Munhata, Shaar Hagolan), the Shephelah (Teluliyot Batash), and the Jordanian plateau (Ain Ghazal, Abu Thawwab).
} 
be looked for in analytical sociology whose models provide explanatory founded regularities transferable by analogy to archeological data as we shall see below.

Let us return to our case study and summarize the archeological data of the Ghassulian southern Levant and their sociological interpretation: new ceremonial norms, visible in the making of new objects with new techniques, appeared and were shared at the scale of the southern Levant, whereas there is limited evidence for hierarchical formation and centralized political power (Rowan and Golden 2009). This wide sharing of new norms raises the question of the historical process by which the Ghassulian population rapidly evolved shared social conventions. The technological analysis of the Ghassulian ceramic assemblages reveals that a same chaîne opératoire, from the clay preparation to the firing, was shared at the scale of the southern Levant. In this respect, the widely shared ceramic tradition of the southern Levant testifies to a same social group wherein it has been transmitted. Technological boundaries have been maintained over centuries suggesting the maintenance of social boundaries, possibly through endogamous matrimonial alliances. The site of Abu Hamid where the different communities met at a given point in time suggests that this broad social group was a homogeneous mixing population (each individual can interact with one another).

If these hypotheses are correct, we are then in a position to use the results obtained by sociologists who have recently worked on the social topology required for populations to share new norms (Centola and Baronchelli 2015). More specifically, they questioned the social structures favorable to the adoption of new social conventions at the population level without large-scale coordination. Experiments were made on the web with players who were presented with a picture of someone and who had to agree on the name to give. The hypotheses were that repeated interaction produces collective agreement among a pair of players and, following a broad range of formal approaches, that "the connectivity of the actor's social networks can influence the collective dynamics of convention formation, ranging from the emergence of competing regional norms that inhibit global coordination to the rapid growth of universally shared social conventions" (Centola and Baronchelli 2015, p. 1990). Three types of networks were tested: (1) spatially embedded social topologies (interactions between actors close spatially), (2) randomly connected topologies (random interactions), and (3) homogeneously mixing populations (each individual can interact with one another). The results show that the network structure that promotes the emergence of shared social norms is the one with the higher connectivity between individuals, i.e., a homogeneously mixing population made up of individuals able to interact with all the individuals of the community. In other words, results show that shared conventions can emerge in complex decentralized systems, without coordinated leadership, when there is a homogenously mixing population and therefore multiple interactions within a dense network structure.

By analogy, it is possible to propose that the shared Ghassulian ceremonial norms emerged as the result of network connectivity, without any large-scale coordination. The rationale is that if archeological data testify to a homogeneous mixing population, then by analogy with the sociological model, it is possible to interpret 
the emergence of common norms as the result of intense interactions, without any global-political coordination. This hypothesis is not contradicted by the ceremonial objects themselves: the major technological innovations (the lost-wax technique and the wheel-coiling technique) were exclusive to ceremonial objects; therefore, they point to belief depositories (e.g., shamans) as suggested by Gilead (2002), but not to any specific politico-religious power. The validation of the archeological interpretation can be evaluated against the validity of the regularity (the model) tested by the study of its generating mechanisms. Indeed, archeological interpretation proceeds by analogy, and in the case of explaining historical processes, the data are too lacunar to test through simulations all the variables which may have played a role in the historical process itself. Only in present-day situations, it is possible to combine empirical studies and simulations for testing the causal role of different variables and interactions.

\section{Conclusion}

In this paper, I have questioned qualitative variables and their use into computational models for revealing the relational structure of societies, knowing that social structures represent conditions of actualization of evolutionary phenomena. I argue that not all the similarity attributes can socially connect sites; among them, technological traditions are the best candidates. They allow not only to trace social connections between sites but also to characterize social topology and population structure. Moreover, they are powerful variables to establish phylogenetic links. They can easily integrate computational models, knowing that any qualitative data can be subsequently quantified (even narratives, see Manzo et al. 2018). The validation of the models obtained lies in the well-founded social significance of the variables and the qualitative analysis of the archeological material.

Validation of the hypotheses explaining evolution processes depends not only on the variables taken to model archeological data but also on the founding of the referential model. Indeed, archeological data are too lacunar and polysemic for obtaining explanations that we could empirically validate. The way out is to interpret them with the help of reference regularities obtained in the domain of present-day societies through simulation methods whose results can be validated against empirical data. The validation of the archeological interpretation lies in both the analogical operation and the founding of the reference regularity transferred to archeological data.

To conclude, the power of computational models for interpreting evolution processes needs not anymore to be demonstrated. However, these models require meaningful variables, and, for this purpose, qualitative analyses of archeological material are more than necessary. Unfortunately, these analyses remain too few, and proper integration of combined relevant proxies is still pending. 


\section{References}

Axelrod, R. (1997). The dissemination of culture a model with local convergence and global polarization. Journal of Conflict Resolution, 41(2), 203-226.

Baldi, J. S. (2017). Collections céramiques du Musée de Préhistoire Libanaise : une étude technique. ArchéOrient - Le Blog. http://archeorient.hypotheses.org/7431.

Bentley, R. A., \& Shennan, S. J. (2003). Cultural transmission and stochastic network growth. American Antiquity, 68(3), 459-485.

Bettinger, R. L., \& Eerkens, J. (1999). Point typologies, cultural transmission, and the spread of bow-and-arrow technology in the prehistoric great Basin. American Antiquity, 64(2), 231-242.

Blake, E. (2014). Dyads and triads in community detection: A view from the Italian bronze age. Les nouvelles de l'archéologie, 135, 28-32.

Borck, L., Mills, B. J., Peeples, M. A., \& Clark, J. J. (2015). Are social networks survival networks? An example from the late pre-Hispanic US Southwest. Journal of Archaeological Method and Theory, 22(1), 33-57.

Bril, B. (2002). L'apprentissage de gestes techniques: ordre de contraintes et variations culturelles. In B. Bril \& V. Roux (Eds.), Le geste technique. Réflexions méthodologiques et anthropologiques (pp. 113-150). Ramonville Saint-Agne: Editions érès.

Brughmans, T. (2010). Connecting the dots: Towards archaeological network analysis. Oxford Journal of Archaeology, 29(3), 277-303.

Brughmans, T. (2013). Thinking through networks: A review of formal network methods in archaeology. Journal of Archaeological Method and Theory, 20(4), 623-662.

Cegielski, W. H., \& Rogers, J. D. (2016). Rethinking the role of agent-based modeling in archaeology. Journal of Anthropological Archaeology, 41(Supplement C), 283-298.

Centola, D. (2015). The social origins of networks and diffusion. American Journal of Sociology, 120(5), 1295-1338.

Centola, D., \& Baronchelli, A. (2015). The spontaneous emergence of conventions: An experimental study of cultural evolution. Proceedings of the National Academy of Sciences, 112(7), 1989-1994.

Centola, D., \& Macy, M. (2007). Complex contagions and the weakness of long ties1. American Journal of Sociology, 113(3), 702-734.

Charbonneau, M. (2018). Technical constraints on technological evolution. In M. J. O'Brien, B. Buchanan, \& M. I. Eren (Eds.), Convergent evolution and stone-tool technology (p.73-89). Cambridge: MIT Press.

Chasan, R., \& Rosenberg, D. (2018). Basalt vessels in Chalcolithic burial caves: Variations in prestige burial offerings during the Chalcolithic period of the southern Levant and their social significance. Quaternary International, 464, 226-240.

Collar, A., Coward, F., Brughmans, T., \& Mills, B. J. (2015). Networks in archaeology: Phenomena, abstraction, representation. Journal of Archaeological Method and Theory, 22(1), 1-32.

Coward, F. (2013). Grounding the net: Social networks, material culture and geography in the Epipalaeolithic and Early Neolithic of the Near East ( 21,000-6,000 cal BCE). In C. Knappett (Ed.), Network analysis in archaeology: New regional approaches to interaction (pp. 247280). Oxford: OUP.

Creswell, R. (1976). Techniques et culture, les bases d'un programme de travail. Techniques \& Culture, 1, 7-59.

Dunnell, R. C. (1978). Style and function: A fundamental dichotomy. American Antiquity, 43, 192-202.

Eerkens, J. W., \& Lipo, C. P. (2005). Cultural transmission, copying errors, and the generation of variation in material culture and the archaeological record. Journal of Anthropological Archaeology, 24(4), 316-334.

Eerkens, J. W., \& Lipo, C. P. (2007). Cultural transmission theory and the archaeological record: Providing context to understanding variation and temporal changes in material culture. Journal of Archaeological Research, 15(3), 239-274. 
Ericson, K. A., \& Lehman, A. C. (1996). Expert and exceptional performance: Evidence from maximal adaptation to task constraints. Annual Review of Psychology, 47, 273-305.

Flache, A., \& Macy, M. W. (2011). Small worlds and cultural polarization. The Journal of Mathematical Sociology, 35(1-3), 146-176.

Flache, A. (2018). Between monoculture and cultural polarization. Agent-based models of the interplay of social influence and cultural diversity. Journal of Archaeological Method and Theory, 25(4), 996-1023.

Gallay, A. (2007). The decorated marriage jars of the inner delta of the Niger (Mali): Essay of archaeological demarcation of an ethnic territory. The Arkeotek Journal (www.thearkeotekjournal.org), 1(1).

Gallay, A. (2011). Pour une ethnoarchéologie théorique. Paris: Editions Errance.

Gandon, E., Roux, V., \& Coyle, T. (2014). Copying errors of potters from three cultures: Predictable directions for a so-called random phenomenon. Journal of Anthropological Archaeology, 33, 99-107.

Gelbert, A. (2003). Traditions céramiques et emprunts techniques dans la vallée du fleuve Sénégal. Ceramic traditions and technical borrowings in the Senegal River Valley. Paris: Editions de la Maison des sciences de l'homme, Editions Epistèmes.

Gilead, I. (1988). The Chalcolithic period in the Levant. Journal of World Prehistory, 2, 397-443.

Gilead, I. (1994). The history of the Chalcolithic settlement in the Nahal Beer Sheva area: The radiocarbon aspect. Bulletin of the American Schools of Oriental Research, 296, 1-13.

Gilead, I. (2002). Religio-magic behavior in the Chalcolithic period of Palestine. In S. Ahituv \& E. D. Oren (Eds.), Aharon Kempinski memorial volume: Studies in archaeology and related disciplines. Beersheva: Ben-Gurion University of the Negev Press.

Gilead, I. (2011). Chalcolithic culture history: The Ghassulian and other entities in the southern Levant. In J. L. Lovell \& Y. Rowan (Eds.), Culture, chronology and the Chalcolithic. Theory and transition (pp. 12-24). Oxford and Oakville: CBRL and Oxbow Books.

Gilead, I., \& Gošić, M. (2015). Unveiling hidden rituals: Ghassulian metallurgy of the Southern Levant in light of the ethnographical record. In K. Rosinska-Balik, A. Ochal-Czarnowicz, M. Czarnowicz, \& J. Debowska-Ludwin (Eds.), Copper and trade in the South-Eastern Mediterranean. Trade routes in the Near East in antiquity (pp. 25-38). Oxford: Archaeopress.

Gjesfjeld, E., \& Phillips, S. C. (2013). Evaluating adaptive network strategies with geochemical sourcing data: A case study from the Kuril Islands. In Network analysis in archaeology: New approaches to regional interaction (pp. 281-305).

Golden, J. (2009). New light on the development of Chalcolithic metal technology in the southern Levant. Journal of World Prehistory, 22(3), 283-300.

Goren, Y. (1995). Shrines and ceramics in chalcolithic Israel: The view through the petrographic microscope. Archaeometry, 37(2), 287-305.

Goren, Y. (2014). Gods, caves, and scholars: Chalcolithic cult and metallurgy in the Judean Desert. Near Eastern Archaeology (NEA), 77(4), 260-266.

Gosselain, O. (2000). Materializing identities: An African perspective. Journal of Archaeological Method and Theory, 7(3), 187-217.

Gosselain, O. (2008). Mother Bella was not a Bella. Inherited and transformed traditions in Southwestern Niger. In M. Stark, B. Bower, \& L. Horne (Eds.), Cultural transmission and material culture. Breaking down boundaries (pp. 150-177). Tucson: Arizona University Press.

Granovetter, M. (1983). The strength of weak ties: A network theory revisited. Sociological Theory, 1(1), 201-233.

Hamilton, M. J., \& Buchanan, B. (2009). The accumulation of stochastic copying errors causes drift in culturally transmitted technologies: Quantifying Clovis evolutionary dynamics. Journal of Anthropological Archaeology, 28(1), 55-69.

Hegmon, M. (1998). Technology, style, and social practice: Archaeological approaches. In M. T. Stark (Ed.), The Archaeology of social boundaries (pp. 264-279). Washington, DC: Smithsonian University Press.

Hodder, I. (1985). Boundaries as strategies: An ethnoarchaeological study. In The archaeology of frontiers and boundaries. New York: Academic Press. 
Jordan, P., \& Shennan, S. (2003). Cultural transmission, language, and basketry traditions amongst the California Indians. Journal of Anthropological Archaeology, 22(1), 42-74.

Knappett, C. (2011). An archaeology of interaction: Network perspectives on material culture and society. Oxford: Oxford University Press.

Knappett, C. (2018). The weakness of strong ties? Communities of practice and network dynamics in the Bronze Age Aegean. Journal of Archaeological Method and Theory, 25(4), 974-995.

Lave, J., \& Wenger, E. (1991). Situated learning: Legitimate peripheral participation. Cambridge: Cambridge University Press.

Levy, T. E. (1995). Cult, metallurgy and rank societies-Chalcolithic period (ca. 4500-3500 BCE). In T.E. Levy (Ed.), The archaeology of society in the Holy Land (pp. 226-244). London: Leicester University Press.

Levy, T. E., \& Holl, A. (1988). Les sociétés chalcolithiques de la Palestine et l'émergence de chefferies. Archives Européennes de Sociologie, XXIX, 283-316.

Levy, T. E., Burton, M. M., \& Rowan, Y. M. (2006). Chalcolithic hamlet excavations near Shiqmim, Negev desert, Israel. Journal of Field Archaeology, 31(1), 41-60.

Lovell, J. L., \& Rowan, Y. M. (Eds.). (2011). Culture, chronology and the Chalcolithic: Theorie and transition. Oxford: Oxbow Books.

Manem, S. (2008). Etude des fondements technologiques de la culture des Duffaits (âge du Bronze moyen). Nanterre: University Paris-Nanterre.

Manzo, G. (2007). Variables, mechanisms, and simulations: Can the three methods be synthesized? Revue Française de Sociologie, 48(5), 35-71.

Manzo, G. (2014). Data, generative models, and mechanisms: More on the principles of analytical sociology. In G. Manzo (Ed.), Analytical Sociology. Actions and Networks (pp. 4-52). Chichester, UK: John Wiley \& Sons.

Manzo, G., Gabbriellini, S., Roux, V., \& M'Mbogori, F. N. J. (2018). Complex contagions and the diffusion of innovations: Evidence from a small-N study. Journal of Archaeological Method and Theory, 25(4), 1109-1164.

Mayor, A. (2010). Ceramic traditions and ethnicity in the Niger Bend, West Africa. Ethnoarchaeology, 2(1), 5-48.

Mesoudi, A. (2009). How cultural evolutionary theory can inform social psychology and vice versa. Psychological Review, 116(4), 929.

Mesoudi, A., \& O’Brien, M. J. (2009). Placing archaeology within a unified science of cultural evolution. In S. J. Shennan (Ed.), Pattern and process in cultural evolution (pp. 21-32). Berkeley and Los Angeles, CA: University of California Press.

Mills, B. J., Clark, J. J., Peeples, M. A., Haas, W. R., Roberts, J. M., Hill, J. B., et al. (2013). Transformation of social networks in the late pre-Hispanic US Southwest. Proceedings of the National Academy of Sciences, 110(15), 5785-5790.

Neiman, F. D. (1995). Stylistic variation in evolutionary perspective: Inferences from decorative diversity and interassemblage distance in Illinois Woodland ceramic assemblages. American Antiquity, 60(1), 7-36.

O'Brien, M. J., \& Bentley, R. A. (2011). Stimulated variation and cascades: Two processes in the evolution of complex technological systems. Journal of Archaeological Method and Theory, 18(4), 309-337.

O’Brien, M. J., Darwent, J., \& Lyman, R. L. (2001). Cladistics is useful for reconstructing archaeological phylogenies: Palaeoindian points from the southeastern United States. Journal of Archaeological Science, 28(10), 1115-1136.

O’Brien, M. J., Lyman, R. L., Glover, D. S., \& Darwent, J. (2003). Cladistics and archaeology. Salt Lake City: University of Utah Press.

O’Brien, M. J., Lyman, R. L., Mesoudi, A., \& VanPool, T. L. (2010). Cultural traits as units of analysis. Philosophical Transactions of the Royal Society of London B: Biological Sciences, 365(1559), 3797-3806.

Östborn, P., \& Gerding, H. (2014). Network analysis of archaeological data: A systematic approach. Journal of Archaeological Science, 46(2), 75-88. 
Östborn, P., \& Gerding, H. (2015). The diffusion of fired bricks in Hellenistic Europe: A similarity network analysis. Journal of Archaeological Method and Theory, 22(1), 306-344.

Perlès, C. (2013). Tempi of change: When soloists don't play together. Arrhythmia in 'continuous' change. Journal of Archaeological Method and Theory, 20(2), 281-299.

Powell, A., Shennan, S. J., \& Thomas, M. G. (2010). Demography and variation in the accumulation of culturally inherited skills. In M. J. O'Brien \& S. J. Shennan (Eds.), Innovation in cultural systems. Contributions from evolutionary anthropology (pp. 137-160). Cambridge, London: The MIT Press.

Rogers, E. M. (1962). Diffusion of Innovations. New York: Free Press.

Rosen, S. A. (1997). Lithics after stone age. A handbook of stone tools from the Levant. Walnut Creek, London, New Delhi: Altamira Press.

Rosenberg, D., \& Shimelmitz, R. (2017). Perforated stars: Networks of prestige item exchange and the role of perforated flint objects in the late Chalcolithic of the Southern Levant. Current Anthropology, 58(2), 295-306.

Rosenberg, D., Chasan, R., \& van den Brink, E. C. (2016). Craft specialization, production and exchange in the Chalcolithic of the southern Levant: Insights from the study of the basalt bowl assemblage from Namir Road, Tel Aviv, Israel. Euroasian Prehistory, 13, 1-23.

Roux, V. (2003). A dynamic systems framework for studying technological change: Application to the emergence of the potter's wheel in the southern Levant. Journal of Archaeological Method and Theory, 10(1), 1-30.

Roux, V. (2010). Technological innovations and developmental trajectories: Social factors as evolutionary forces. In M. J. O’Brien \& S. J. Shennan (Eds.), Innovation in cultural systems. Contributions from evolutionary anthropology (pp. 217-234). Cambridge, London: The MIT Press.

Roux, V. (2015). Standardization of ceramic assemblages: Transmission mechanisms and diffusion of morpho-functional traits across social boundaries. Journal of Anthropological Archaeology, 40(4), 1-9.

Roux, V. (2016). Des Céramiques et des Hommes. Décoder les assemblages archéologiques. Nanterre: Presses Universitaires de Paris Ouest.

Roux, V. (2019). The Ghassulian ceramic tradition: A single chaîne opératoire prevalent throughout the Southern Levant. Journal of Eastern Mediterranean Archaeology and Heritage Studies, 7(1), 23-43.

Roux, V., \& Courty, M. A. (2005). Identifying social entities at a macro-regional level: Chalcolithic ceramics of South Levant as a case study. In A. Livingstone Smith, D. Bosquet, \& R. Martineau (Eds.), Pottery manufacturing processes: Reconstruction and interpretation (pp. 201-214). Oxford: BAR International Series.

Roux, V., \& Courty, M. A. (2007). Analyse techno-pétrographique céramique et interprétation fonctionnelle des sites: un exemple d'application dans le Levant Sud Chalcolithique. In A. Bain, J. Chabot, \& M. Mousette (Eds.), Recherches en archéométrie: la mesure du passé (pp. 153-167). Oxford: Archaeopress.

Roux, V., Bril, B., Cauliez, J., Goujon, A. L., Lara, C., de Saulieu, G., \& Zangato, E. (2017). Persisting technological boundaries: Social interactions, cognitive correlations and polarization. Journal of Anthropological Archaeology, 48(4), 320-335.

Rowan, Y. M., \& Golden, J. (2009). The Chalcolithic period of the Southern Levant: A synthetic review. Journal of World Prehistory, 22(1), 1-92.

Shennan, S. J. (2001). Demography and cultural innovation: A model and its implications for the emergence of modern human culture. Cambridge Archaeological Journal, 11(1), 5-16.

Shennan, S. J. (2002). Genes, memes and human history: Darwinian archaeology and cultural evolution. London: Thames \& Hudson.

Shennan, S. (2013). Lineages of cultural transmission. In E. Roy, S. J. Lycett, \& S. E. Johns (Eds.), Understanding cultural transmission in anthropology: A critical synthesis (pp. 346-360). Oxford: Berghahn Books.

Shennan, S. J., \& Steele, J. (1999). Cultural learning in hominids: A behavioural ecological approach. In H. Box \& K. Gibson (Eds.), Mammalian social learning. Symposia of the zoological society of London 70 (pp. 367-388). Cambridge: Cambridge University Press. 
Shennan, S. J., \& Wilkinson, J. R. (2001). Ceramic style change and neutral evolution: A case study from Neolithic Europe. American Antiquity, 66(4), 577-593.

Shennan, S. J., Crema, E. R., \& Kerig, T. (2015). Isolation-by-distance, homophily, and "core" vs. "package" cultural evolution models in Neolithic Europe. Evolution and Human Behavior, 36(2), 103-109.

Stark, M. T. (Ed.). (1998). The archaeology of social boundaries. Washington, London: Smithsonian Institution Press.

Stark, M. T., Bishop, R. L., \& Miska, E. (2000). Ceramic technology and social boundaries: Cultural practices in Kalinga clay selection and use. Journal of Archaeological Method and Theory, 7(4), 295-332.

Stark, M. T., Bowser, B. J., \& Horne, L. (Eds.). (2008). Cultural transmission and material culture. Breaking down boundaries. Tucson: The University Arizona Press.

Tehrani, J. J., \& Collard, M. (2009). On the relationship between interindividual cultural transmission and population-level cultural diversity: A case study of weaving in Iranian tribal populations. Evolution and Human Behavior, 30(4), 286-300.

Tehrani, J. J., \& Riede, F. (2008). Towards an archaeology of pedagogy: Learning, teaching and the generation of material culture traditions. World Archaeology, 40(3), 316-331.

Valente, T. W. (1996). Social network thresholds in the diffusion of innovations. Social Networks, $18(1), 69-89$.

Valente, T. W. (1999). Network models of the diffusion of innovations. Cresskill: Hampton Press.

Wenger, E. (2000). Communities of practice and social learning systems. Organization, 7(2), $225-246$. 